\title{
Confirmatory factor analysis of perceived risk factors for crowd safety in large buildings
}

\author{
Mohammed Alkhadim ${ }^{1}$, Kassim Gidado ${ }^{2}$ and Noel Painting ${ }^{3}$ \\ ${ }^{1}$ University of Brighton, School of Environment \& Technology, BN2 4GJ, UK. M.Al- \\ Khadim@brighton.ac.uk \\ ${ }^{2}$ University of Brighton, School of Environment \& Technology, BN2 4GJ, UK. \\ K.I.Gidado@brighton.ac.uk \\ ${ }^{3}$ University of Brighton, School of Environment \& Technology, BN2 4GJ, UK. \\ N.J.Painting@brighton.ac.uk
}

\begin{abstract}
In large buildings or spaces used for large events, crowd safety is one of the most important concerns for facilities management. In the past decades, there have been crowd disasters in venues such as sport stadiums, concert halls, and at religious events the world over. The user of such facilities during mass gatherings can be exposed to health and safety risk, which can be mitigated by using effective risk management as a component of facilities management. A lot of emphasis is given to objective safety, but research has shown that the user's perceived (subjective) safety is also an important factor that cannot be overlooked. This research has identified the crowds' perceived risk factors for a selected large space facility. The paper applied confirmatory factor analysis to test the theoretical pattern of the variables loading on a developed construct to show how well these factors match reality. Twelve perceived risk factors to crowd safety have been tested and verified.
\end{abstract}

Keywords: facilities management, risk management, crowd safety, confirmatory factor analysis.

\section{Introduction}

Crowd safety is a major concern in facilities management and to those who attend events in large buildings and at venues such as sport stadiums, concert halls, and religious events (i.e. Hajj). Crowd safety can be achieved when there are no injurious or serious incidents outcomes experienced by any individual in the crowd. A bad crowd safety experience can become a disaster when many people get 
seriously injured or killed from trampling or crushing or other causes. Moller et al. (2006) argued that the higher the risk the lower is the safety. In large buildings used by large numbers of people, there are many threats and different levels of risk that require effective management. Dickie (1995) stressed that a flaw or hazard in large buildings or spaces during an event has resulted in many crowd disasters across the world. The Center for Research on the Epidemiology of Disasters (CRED) (2003), determined several criteria for disasters and at least one of the following must be fulfilled: 10 or more people killed; 100 or more people get injured; declaration of a state of emergency; a call for international assistance.

Two key existing crowd safety models were identified; FIST (Fruin, 1993) and six dimensions and loci of crowd disaster (Chukwuma \& Kingsley, 2014). These models include important factors that may cause risk to crowd safety and lead to crowd disaster. The acronym FIST is defined as: Force (F), Information (I), Space (S) and Time (T) while the six dimensions and loci of crowd disaster model involve 6 factors (Stampede, Riot, Structural and Mechanical failure, Terrorist attacks, Explosion (fire, chemical) and Natural disaster). Two more factors have been added from analyses of previous studies and major crowd incidents including user behavior and perceived safety. Each of these 12 factors is individually described as a sub-section in section 2 of this paper.

The research in this paper used the Holy Mosque during Hajj event as a case study in order to test, verify and to measure the reliability of the factors. The Holy Mosque is the largest mosque in the world, at approximately 356,800 square metres and has 32 doors including 4 main doors. It can accommodate around 1.2 million worshipers at the same time. Hajj is one of the five pillars of Islam which is mainly concentrated in four holy places: the Holy Mosque, the Mina, Muzdalifah and Arafat (Alsolami et al., 2016). It takes place once a year in a period ranging between 4 to 6 days. The Holy Mosque is a large building and has unique characteristics that facilitate an indepth understanding of risk factors that may affect crowd safety.

\section{Perceived Risk Factors to Crowd Safety}

\subsection{Perceived risk of Stampede (PST)}

Human stampede is a phenomenon that has occurred many times around the world. It refers to the hazard that can take place during large events where people gather. Two forms of stampede have been identified; one happens if people panic when attempting to escape from danger whereas the second form occurs when people rush toward something needed or desired at the event. Based on previous studies, human stampede has been associated with grave consequences such as loss of life, serious injury, property damage, psychological trauma and distress 
(Chukwuma \& Kingsley, 2014). Stampede can occur in many types of large gatherings including political rallies, social events (funerals, music events, shop sales etc.), sporting events (soccer matches, athletic competitions, etc.), religious events (pilgrimages, etc.), job selection screening or test exercises, emergency situations (terrorist group) or natural disaster (Floods, earthquakes, hurricane, etc.) (Still, 2016). These studies have reported that religious events have seen the worst incidents of human stampede with most incidents occurring in developing countries such as India and Saudi Arabia. According to Chukwuma \& Kingsley (2014) "human stampede is a typical instance of crowd disaster". Pushing, trampling and crushing are associated with human stampede. Sociological theorists have stressed that individuals lose their sense of responsibility during a stampede situation (Miller, 2015). Studies on crowd disaster have shown that when the crowds need to turn in order to change the direction (e.g. in corners and stairwells), there is a risk of trampling and/or stampede to occur. They further state that when such restricted passage has sudden changes in the escape direction, it could also trigger trampling and stampede as people rush to flee (Shiwakoti \& Sarvi, 2013).

\subsection{Perceived risk of Riot (PR)}

Riot is a risky phenomenon, with many possible causes of incidents. The National Disaster Management Authority of India (2014) defined riot as "a form of civil disorder characterized often by what is thought of as disorganized groups lashing out in a sudden and intense rash of violence against authority, property or people". It has frequently occurred in some part of the world. One example of a riot occurred in 1992 in Los Angeles in which resulted in 52 people dead and 2500 injured as well as at least $\$ 446$ million in property damage (DiPasquale \& Glaeser, 1996). Riots are often aggressive and violent, they usually start peacefully and then transform into a violent mob. Once they start, it is likely impossible to control them.

\subsection{Perceived risk of Structural Failure (PSF)}

The failure of any temporary or permanent structure in a crowded venue can have an overwhelming effect. It has been indicated that structural failure is not uncommon. Insufficient design, poor construction, inadequate codes of practice and overloading have all caused significant failures (Petroski, 1992). According to the National Disaster Management Authority of India (NDMA) (2014), structural failures have also been cited as reason for crowd disasters on numerous occasions.

\subsection{Perceived risk of Terrorist Attack (PTA)}

In recent decades, terrorism has been increasing worldwide. Most studies on terrorism have lacked theoretical and empirical analysis. Furthermore, accepted 
definitions of terrorism are unclear but several elements are shared in common. These common elements refer to the violence or threat of actions that result in fatalities and serious injuries. Although many terrorist events seem irrational, these events must have been planned. According to the current definition of the U.S. Department of Defense (US DoD, 2015): terrorism is "the unlawful use of violence or threat of violence, often motivated by religious, political, or other ideological beliefs, to instill fear and coerce governments or societies in pursuit of goals that are usually political." A further definition is given by Tilly (2004), who described terror as "political strategy" which is the "asymmetrical deployment of threats and violence against enemies using means that fall outside the forms of political struggle routinely operating within some current regime". The Oxford English Dictionary defines terror as 'the state of being terrified or greatly frightened; intense fear, fright or dread'. Nowadays, terrorism has become one of the main risk dimensions which requires safety planning. It is a veritable threat which targets public venues particularly, crowded places including sports and, religious events.

\subsection{Perceived risk of Explosion (fire/chemical) (PE)}

According to Shaluf (2008), fire and explosion are major accidents which are classified as technological disaster. The International Labour Office (ILO) (1988) defined major accident as "an occurrence such as a major emission, fire or explosion resulting from uncontrolled developments in the course of an industrial activity, leading to a serious danger to man, immediate or delayed, inside or outside the establishment, and to the environment, and involving one or more dangerous substances". Many technological disasters have occurred around the world, such as: the fire that swept through a tent in Mina, Makkah during Hajj in 1997; the Gothenburg, Sweden, Disco in 1998; the Rhode Island Rock concert in 2003 (Still, 2016). Sime (1999) reviewed a number of disaster cases with respect to the fire and behavior of the people within the fire situation. These disasters included the Beverly Hills Supper Club in 1977; Summerland Woolworth's in 1937; Bradford King's Cross in 1985 (Sime, 1995). In these cases the fire made people to panic in response to save their lives; and it is the panic that resulted in fatalities. For example, due to behavior of the people who panicked at the Beverly Hills Supper Club event in Kentucky, USA in 1977, 300 people were stampeded. This study therefore attempts to assess the impact of the potential risk of fire and explosion on crowd behavior.

\subsection{Perceived (risk of) Natural Disaster (PND)}

Natural disasters are catastrophic events which occur due to natural forces and are not controllable by mankind. Examples include flood, climate change (heat waves or cold waves), strong wind, volcanic eruptions, tornados, earthquakes, etc. (Shaluf \& Ahmadun, 2006). In the last few decades, natural disasters have increased worldwide, particularly in the developing countries. Natural disasters 
present a serious risk and result in heavy loss of life and property damage. They pointed out that "floods are among the greatest natural disasters known to mankind". Based on Shaluf (2007), Asia and the Pacific are the regions most exposed to natural disasters. Most natural disasters result from heavy rains. Another natural disaster threat comes from climate change. Several studies have shown the significant association between climate change (e.g. high temperature) and mortality (Dear \& Wang, 2015). Based on the Intergovernmental Panel on Climate Change7 report in 2014, the increase of heat and decrease of cold due to climate change will result in increase of mortality in some parts of the world (Dear \& Wang, 2015). For example, in the summer of 2003 it was reported that 70,000 Europeans died due to heat waves (Robine et al., 2008). It is expected that the intensity of heat waves and the average of global temperatures will be increased as a result of climate change (The Regional Office for Europe of the World Health Organization, 2011). Numerous studies have discovered that exposure to heat waves may cause cramps, fluid loss, fainting, heat exhaustion, dehydration, heat stress, heat stroke and ultimately mortality (Lowe et al., 2011). Within a short time of exposure to high temperatures, people affected by heat may suffer fatalities (Diaz et al., 2006). The elderly (aged 60 years or older), particularly women, and those with chronic lung diseases are more affected (Lowe et al., 2011). High temperatures are likely to affect people physically and psychologically. Anderson (2001) underlined that hot temperatures can increase aggressive behavior by directly increasing feelings of hostility and indirectly increase aggressive thoughts. This could be worse within large gathering events including sport, religious and political events.

\subsection{Perceived risk of Force $(\mathrm{PF})$}

Perceived force refers to the feeling of the individual while within a crowd that may be produced by either hearing, seeing or sensing the force. The force may reach such a high level that it cannot be controlled or resisted because of crowd pressure. It has been emphasized that crowd compression, compressive asphyxia and a subsequent loss of footing or inability to move are the main reasons of deaths during an event (not by trampling) (Still, 2016). Berlonghi, (1995) claims that serious injuries and fatalities may occur from suffocation when people in a crowd are being swept along with movement and compressed. Generally, the forces that can be created when density exceeds a certain level may lead to a serious incident.

\subsection{Perceived risk of Poor Information (PPI)}

In large buildings, it is crucial to obtain real time information about the crowd condition including crowd action, reactions whether real or perceived. Information communicated to - or withheld from - the crowd can influence their perceived safety. The Challenger et al. (2009b) states that "communicating with the crowd is essential in maintaining order and managing behaviour". Sime (1999) stressed that 
poor information prior to or during an event has led to many crowd incidents. Information comprises all means of communication such as signs and announcements. Fruin (1993) suggests that actions and training of personnel, sights and sounds all affect group perceptions. Setting up a communication centre and a centralized crowd management system is good practice. Experts have highlighted that real-time information and communication are significant factors in minimizing risk of crowd disasters.

\subsection{Perceived risk of Insufficient Space (PIS)}

Fruin (1993) claimed that architects and engineers typically pay minimal attention to planning people's movement and perceptions but greater emphasis to meeting the local building codes regarding space in large buildings involving physical facilities, seating areas, corridors, stairs, escalators, standing areas and lifts. It has been shown that human psychology usually undergoes a change when the capacity becomes high and the venue does not have enough space to accommodate the crowd. Generally, when the individuals within a crowd perceive risk or a possible disaster, they panic and move to an exit ignoring alternative exits made available. Fruin (1993) stated that within a high- density crowd it is difficult to describe the psychological and physiological pressure, and individuals may lose their control. Several studies have emphasized that crowd density has an effect on perceived safety and on people's behavior (Alnabulsi \& Drury, 2014). It has been argued that insufficient or poor use of space is considered a key risk factor to crowd safety.

\subsection{Perceived risk of Poor Real Time Management (PPRTM)}

Poor real time information and interventions are key risk factors to crowd safety (Fruin ,1993). Lloyd et al. (2017) stated that failure to detect the behavior of the crowd at the right time can lead to serious incidents. Time plays an important role, for example, the inflow of the pedestrian compared to the rapid egress is much less while the pedestrian are leaving an event. It has been emphasized that the flow of the pedestrians must not exceed the capacity of the spaces available (Mehta, 2013). UK Cabinet Office guidance (2009) has indicated that "lack of consideration is sometimes given to how crowd flow and density can be successfully managed by controlling timings".

\subsection{Perceived Safety (PS)}

Feeling unsafe during an event can drive people to panic from real or perceived risk through acting unusually by pushing and shoving (Challenger et al., 2009b). Studies in urban design have identified several factors that may have an influence 
on perceived safety including characteristics of the environment, the physical condition, and the configuration of spaces (Mehta, 2013). The perception could differ from one person to another, for instance women and older people have a more diverse sense of safety compared with others. Crowd studies, have found that the perceived crowding which is defined by Kim et al. (2016) as "the psychological counterpart to population density" is closely tied to perceived safety. There is a negative correlation between perceived safety and perceptions of crowding; people's sense of safety declines as perceptions of crowding increase (Tseng et al., 2009).

\subsection{Crowd (Users) Behaviour (UB)}

Crowd behaviour refers to the way in which persons act or behave towards others. Berlonghi, (1995) suggested important factors that can influence crowd behaviors and play an important role in designing management and crowd control at events. These factors include location and time of the event, size of the crowd, crowd mobility, demographics of the crowd (e.g. age, gender), schedule of event activities, crowd movement models, geometry of the location, weather conditions and density of crowd in different areas. At some events, the crowd can turn into a mob and become aggressive. "The aggressive behaviour may be in response to such strictures or emotional triggers such as elation, fear, or anger, and may be exaggerated by impairments such as drug or alcohol intoxication and lack of accurate information. Aggressive behavior may also result from physical discomfort due to environmental conditions such as heat, cold, noise, etc., and may become more likely if others are displaying aggressive behavior and are either rewarded or go unpunished" (Silvers, 2008). Psychological experiments, they have shown that when people get a high level of arousal responsibility is diffused, people may act irrationally and not be able to control their own behaviour (Berlonghi, 1995). Those people may start throwing objects, screaming and pushing people while some may turn into mobs carrying out theft, vandalism, rioting, group violence leading to a potential crowd disaster (Myers, 1990).

\section{Method}

Confirmatory Factor Analysis (CFA) is used as statistical technique for this study. This statistical technique does not specify variables to factors instead the factors are determined by the researcher based on the theory being tested prior to any results being obtained. CFA is applied to test the theoretical pattern of the variables loading on specific constructs and to show how well the theoretical specification of the factors can match the reality (the actual data). CFA enables the research to accept or reject the theory that has been studied (Hair et al., 2010). 
1,940 pilgrims (both local and foreign) were surveyed within the zone of Makkah during the Hajj of the year 2016 (1437 Arabic Calendar). The questionnaire covered thirteen sections: section one is background information and sections two to thirteen are designed to test the perceived risk factors to crowd safety. The items included in the questionnaire were adapted from (Alnabulsi \& Drury, 2014; Fruin, 1993; Rahmat et al., 2011; Chukwuma \& Kingsley, 2014). All the items were measured using a 5 -point Likert scale $(1=$ strongly disagree to $5=$ strongly agree; or $1=$ never occur to $5=$ almost always occurs). Several items were modified to attain the aim of the research.

\section{$4 \quad$ Results and discussion}

The data was analysed using the Statistical Packages for the Social Sciences (SPSS) and Analysis of Moment Structure (AMOS) for descriptive analysis and CFA, respectively.

Having ensured that the collected data was clean and normally distributed, the Kaiser-Meyer-Olkin (KMO) and Bartlett's Test was used to check whether the data was appropriate to continue with a CFA procedure (Raston et al., 2010). KMO and Bartlett's Test of Sphericity, as shown in Table 1, indicates that all values of independent and dependant variables have achieved the minimum level of 0.60 with a significant $\mathrm{p}$-value $\mathrm{p}<0.05$.

Table 1. KMO and Bartlett's Test.

\begin{tabular}{lllll}
\hline Variables & $\begin{array}{l}\text { Kaiser-Meyer-Olkin Measure } \\
\text { of Sampling Adequacy }\end{array}$ & Bartlett's Test of Sphericity & \\
\hline & & Approx. Chi-Square & DF & P-value \\
\hline PF & .897 & 7078.170 & 15 & .000 \\
PPI & .887 & 7012.245 & 10 & .000 \\
PIS & .837 & 4611.010 & 10 & .000 \\
PPTM & .844 & 4576.378 & 10 & .000 \\
PST & .743 & 2673.446 & 15 & .000 \\
PR & .713 & 1856.586 & 3 & .000 \\
PSF & .717 & 1854.211 & 6 & .000 \\
PTA & .811 & 3207.841 & 6 & .000 \\
PE & .667 & 1736.834 & 3 & .000 \\
PND & .748 & 2474.099 & 10 & .000 \\
UB & .806 & 3989.596 & 10 & .000 \\
PS & .861 & 4748.904 & 28 & .000 \\
\hline
\end{tabular}




\section{Confirmatory Factor Analysis (CFA)}

When undertaking a CFA, it is necessary to assess the unidimensionality, convergent and discriminant validity, as well as reliability (Awang, 2015). The unidimensionality should be made first before assessing the convergent and discriminant validity, and reliability. Unidimensionality refers to the measurement items that have acceptable factor loading for the latent construct which is 0.60 and above (Hu \& Bentler, 1999; Awang, 2015).

Figure 1 presents the structural model, some modifications have been made based on Modification Indices (MI). Several items have been deleted one at a time and others have been covarying the error terms with the purpose of achieving the minimum fitness index.

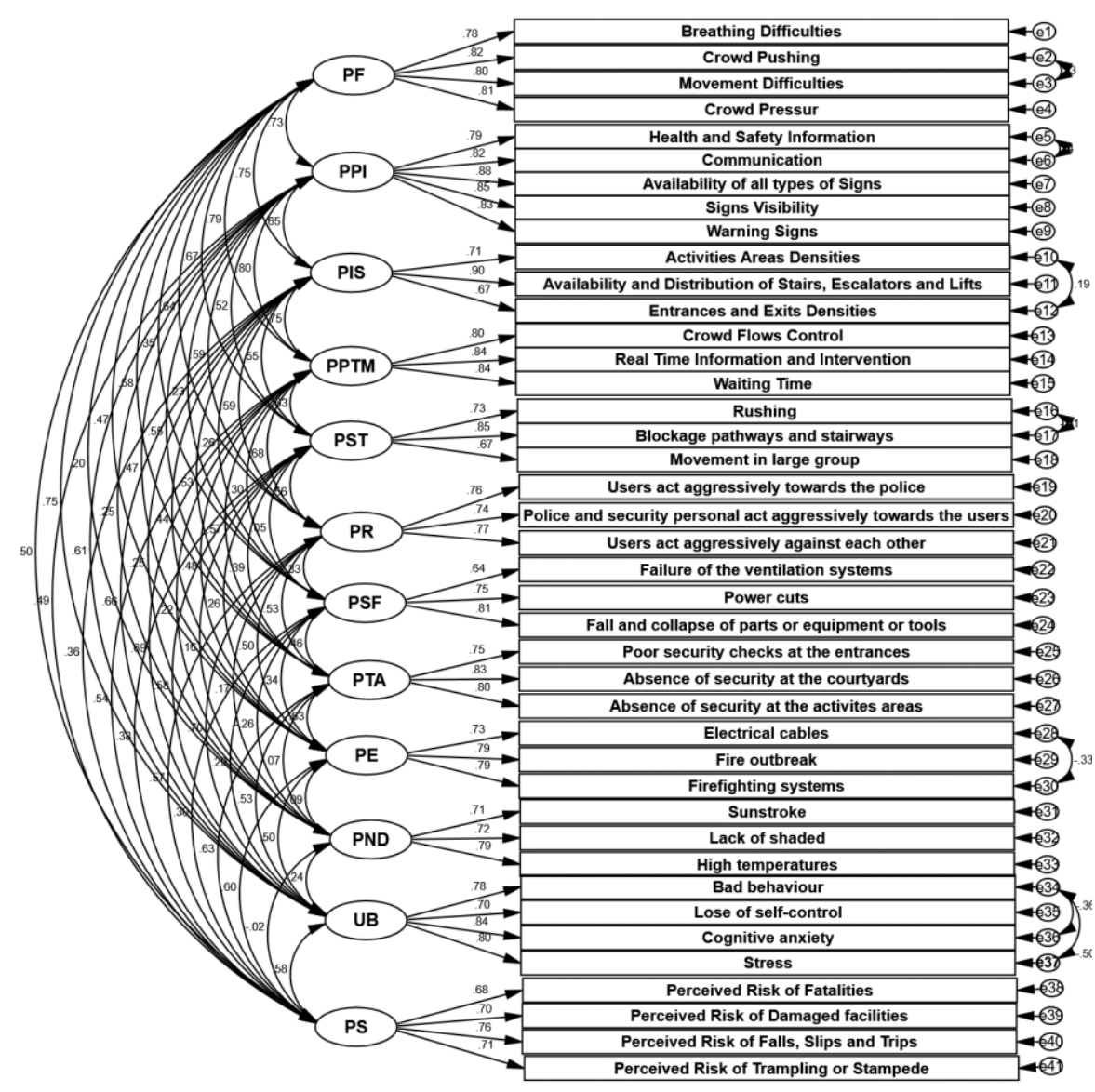

Fig. 1 The Path Diagram on the Confirmatory Factor Analysis for all variables 


\section{Convergent Validity}

To establish convergent validity, the model fit must be adequate, and the average variance extracted (AVE) must exceed 0.50 (Hair et al., 2010). Table 2 provides the result of the model fit measures. Hu \& Bentler, (1999) and Awang (2015) recommend a comparative fit index $(\mathrm{CFI}) \geq 0.90$, standardized root mean square residual $(\mathrm{SRMR}) \leq 0.08$, and root mean square error of approximation (RMSEA) $\leq$ 0.06 for acceptable model fit. The values included in Table 2 indicate that the model is fit and all measures of CFI $=0.940, \mathrm{SRMR}=0.046$, and $\mathrm{RMSEA}=0.045$ have achieved the required level. Also, the results of AVE for all constructs as illustrated in Table 4 have achieved the standard minimum required level of 0.50 .

Table 2. Fit Indices.

\begin{tabular}{llll}
\hline Measure & Estimate & Threshold & Interpretation \\
\hline CFI & 0.940 & $>0.95$ & Good fit \\
SRMR & 0.046 & $<0.08$ & Good fit \\
RMSEA & 0.045 & $<0.06$ & Good fit \\
\hline
\end{tabular}

\section{Discriminant Validity}

To establish discriminant validity three criteria must be met (Gaskin, 2016a; Hair et al., 2010). The Fornell-Larcker test needs the square root AVE for each construct to be greater than any inter-construct correlations (Fornell \& Larcker, 1981). All constructs for this study have met this criterion. The square root of the AVE of the construct is greater than its estimates of correlation as presented in Table 3.

Table 3. Discriminant Validity Fornell-Larcker test.

\begin{tabular}{|c|c|c|c|c|c|c|c|c|c|c|c|c|}
\hline Construct & 1 & 2 & 3 & 4 & 5 & 6 & 7 & 8 & 9 & 10 & 11 & 12 \\
\hline PF & 0.802 & & & & & & & & & & & \\
\hline PPI & 0.735 & 0.835 & & & & & & & & & & \\
\hline PIS & 0.746 & 0.655 & 0.770 & & & & & & & & & \\
\hline PPTM & 0.789 & 0.802 & 0.746 & 0.828 & & & & & & & & \\
\hline PST & 0.669 & 0.523 & 0.547 & 0.627 & 0.753 & & & & & & & \\
\hline PR & 0.637 & 0.591 & 0.587 & 0.684 & 0.557 & 0.760 & & & & & & \\
\hline PSF & 0.354 & 0.234 & 0.260 & 0.301 & 0.045 & 0.331 & 0.737 & & & & & \\
\hline PTA & 0.578 & 0.551 & 0.528 & 0.573 & 0.388 & 0.532 & 0.458 & 0.794 & & & & \\
\hline PE & 0.468 & 0.468 & 0.438 & 0.480 & 0.257 & 0.504 & 0.339 & 0.634 & 0.768 & & & \\
\hline PND & 0.196 & 0.253 & 0.253 & 0.218 & 0.164 & 0.175 & -0.260 & -0.068 & -0.091 & 0.741 & & \\
\hline UB & 0.749 & 0.608 & 0.662 & 0.692 & 0.584 & 0.696 & 0.292 & 0.532 & 0.496 & 0.236 & 0.785 & \\
\hline
\end{tabular}




\begin{tabular}{ccccccccccccc}
\hline & & & & & & & & & & & & \\
PS & 0.502 & 0.492 & 0.360 & 0.542 & 0.381 & 0.569 & 0.302 & 0.633 & 0.599 & -0.019 & 0.581 & $\mathbf{0 . 7 1 3}$ \\
\hline
\end{tabular}

The other two criteria for discriminant validity that must also be met are the Maximum Shared Squared Variance (MSV) and Average Shared Squared Variance (ASV). Hair et al., (2010) recommend that MSV and ASV must be less than the results of AVE (MSV $<$ AVE, ASV $<$ AVE). The results of ASV and MSV as detailed in Table 4 indicate that our measurement model is valid.

\section{Reliability and Construct Validity}

Table 4 presents the results of the reliability and construct validity test. Two reliability tests have been undertaken for this study: composite reliability $(\mathrm{CR})$ and Cronbach's alpha. Both tests were used to guarantee the reliability of the data before conducting further analysis. CR is more accurate than Cronbach's alpha because it does not assume that the loadings or error terms of the items are equal (Chin et al., 2003). The CR test has met the standard minimum threshold of 0.60 .

Table 4. Reliability and construct validity.

\begin{tabular}{|c|c|c|c|c|c|c|c|}
\hline Constructs & $\begin{array}{r}\text { CR } \\
\text { (above } \\
0.60 \text { ) }\end{array}$ & $\begin{array}{l}\text { AVE } \\
\text { (above } \\
0.50 \text { ) }\end{array}$ & $\begin{array}{l}\text { Cronbach } \\
\text { (above 0.7) }\end{array}$ & MSV & ASV & $\begin{array}{c}\text { Convergent } \\
\text { validity } \\
\mathrm{CR}>\mathrm{AVE} \\
\mathrm{AVE}>0.50\end{array}$ & $\begin{array}{l}\text { Discriminant } \\
\text { validity } \\
\text { MSV }<\text { AVE } \\
\text { ASV }<\text { AVE }\end{array}$ \\
\hline $\mathrm{PF}$ & 0.878 & 0.644 & 0.886 & 0.622 & 0.37 & Yes & Yes \\
\hline PPI & 0.920 & 0.697 & 0.922 & 0.643 & 0.32 & Yes & Yes \\
\hline PIS & 0.811 & 0.593 & 0.824 & 0.556 & 0.31 & Yes & Yes \\
\hline PPTM & 0.867 & 0.685 & 0.866 & 0.643 & 0.38 & Yes & Yes \\
\hline PST & 0.796 & 0.568 & 0.748 & 0.448 & 0.22 & Yes & Yes \\
\hline PR & 0.803 & 0.577 & 0.804 & 0.484 & 0.31 & Yes & Yes \\
\hline PSF & 0.779 & 0.543 & 0.774 & 0.210 & 0.09 & Yes & Yes \\
\hline PTA & 0.836 & 0.630 & 0.833 & 0.403 & 0.27 & Yes & Yes \\
\hline PE & 0.811 & 0.590 & 0.780 & 0.403 & 0.21 & Yes & Yes \\
\hline PND & 0.785 & 0.549 & 0.784 & 0.068 & 0.04 & Yes & Yes \\
\hline UB & 0.864 & 0.616 & 0.834 & 0.561 & 0.33 & Yes & Yes \\
\hline PS & 0.805 & 0.508 & 0.804 & 0.401 & 0.23 & Yes & Yes \\
\hline
\end{tabular}

The model also confirms that all Cronbach's Alpha values for the construct as given in Table 4 are above the recommended value of 0.70 (Gaskin, 2016). This indicates the acceptability of internal consistency and confirms that all the items used in the model are technically free from the errors (Hair et al., 2010). 
Table 5. Factor loading for items.

\begin{tabular}{|c|c|c|}
\hline Constructs & Items & Factor Loading \\
\hline \multicolumn{3}{|l|}{$\mathrm{PF}$} \\
\hline & Breathing Difficulties & 0.78 \\
\hline & Crowd Pushing & 0.82 \\
\hline & Movement Difficulties & 0.80 \\
\hline & Crowd Pressure & 0.81 \\
\hline \multicolumn{3}{|l|}{ PPI } \\
\hline & Health and Safety Information & 0.80 \\
\hline & Communication & 0.82 \\
\hline & Availability of all types of Signs & 0.88 \\
\hline & Signs Visibility & 0.85 \\
\hline & Warning Signs & 0.83 \\
\hline \multicolumn{3}{|l|}{ PIS } \\
\hline & Activities Areas Densities & 0.71 \\
\hline & $\begin{array}{l}\text { Availability and Distribution } \\
\text { of Stairs, Escalators and Lifts }\end{array}$ & 0.91 \\
\hline & Entrances and Exits Densities & 0.67 \\
\hline \multicolumn{3}{|l|}{ PPTM } \\
\hline & Crowd Flows Control & 0.80 \\
\hline & Real Time Information and Intervention & 0.84 \\
\hline & Waiting Time & 0.84 \\
\hline \multicolumn{3}{|l|}{ PST } \\
\hline & Rushing & 0.73 \\
\hline & Blockage pathways and stairways & 0.85 \\
\hline & Movement in large group & 0.67 \\
\hline \multicolumn{3}{|l|}{ PR } \\
\hline & Users act aggressively towards the police & 0.76 \\
\hline & Police and security personal act aggressively towards the users & 0.74 \\
\hline & Users act aggressively against each other & 0.78 \\
\hline \multicolumn{3}{|l|}{ PSF } \\
\hline & Failure of the ventilation systems & 0.65 \\
\hline & Power cuts & 0.75 \\
\hline & Fall and collapse of parts or equipment or tools & 0.81 \\
\hline \multicolumn{3}{|l|}{ PTA } \\
\hline & Poor security checks at the entrances & 0.75 \\
\hline & Absence of security at the courtyards & 0.83 \\
\hline & Absence of security at the activities areas & 0.80 \\
\hline PE & & 0.73 \\
\hline & Electrical cables & 0.79 \\
\hline & Fire outbreak & 0.79 \\
\hline
\end{tabular}




\begin{tabular}{lll}
\hline & Firefighting systems & \\
\hline PND & & 0.71 \\
\hline & Sunstroke & 0.72 \\
\hline & Lack of shaded & 0.79 \\
\hline High temperatures & \\
\hline UB & & 0.78 \\
\hline & Bad behavior & 0.70 \\
\hline & Loss of self-control & 0.85 \\
\hline Cognitive anxiety & 0.80 \\
\hline Stress & & \\
\hline & Perceived Risk of Fatalities & 0.68 \\
\hline & Perceived Risk of Damaged facilities & 0.71 \\
\hline & Perceived Risk of Falls, Slips and Trips & 0.76 \\
\hline & Perceived Risk of Trampling or Stampede & 0.71 \\
\hline
\end{tabular}

Overall, the result of the assessment of the measurement model shows solid evidence of unidimensionality, convergent validity, discriminant validity, and reliability.

\section{Conclusion}

This research presents the results of confirmatory factor analysis examining twelve important factors that may cause risk to crowd safety. The theoretical pattern of the variables loading on a developed construct were tested confirming the validity and reliability of the model. It clearly shows that the items on each construct of the study are reliable and the model has got enough measurement properties. Forty one items were identified with an acceptable factor loading of at least 0.60 . The results of CFA show acceptable evidence on the FIST, the six dimensions and loci of crowd disaster, and the two additional items of user behavior and perceived safety. The results of good internal consistency and validity of the constructs support the potential use of these 12 factors for large buildings used for hosting large events. For instance, the model can be used as indicators to evaluate large buildings used for large numbers of people whether it involved any of these risks. Many crowd disasters have occurred across the world where hazards were either not recognized or completely ignored. We concluded therefore that these 12 factors and items must be taken into account for managing large buildings and spaces in order to enhance crowd safety and reduce risk. 


\section{Acknowledgements}

The authors gratefully acknowledge the support of the "The Custodian of The Two Holy Mosques Institute for Hajj \& Umrah Research, Makkah”.

\section{References}

Alnabulsi, H. and Drury, J. (2014). Social identification moderates the effect of crowd density on safety at the Hajj. Proceedings of the National Academy of Sciences of the United States of America (on-line), 111: 9091-9096. http://www.ncbi.nlm.nih.gov/pubmed/24927593.

Alsolami, B., Embi, M. R. and Enegbuma, W. I. (2016). The Influence of Personal Factors on Hajj Crowd Perception among African Pilgrim Group in Mina. Indian Journal of Science and Technology, 9: 9.

Anderson, C. A. (2001). Heat and Violence. Current Directions in Psychological Science (on-line), 10: 33-38. http://cdp.sagepub.com/lookup/doi/10.1111/1467-8721.00109.

Awang, Z. (2015). SEM Made Simple: A Gentle Approach to Learning Structural Equation Modeling. MPWS Rich Publication 2015.

Berlonghi, A. E. (1995). Understanding and planning for different spectator crowds. Safety Science, 18: 239-247.

Center for Research on the Epidemiology of Disasters (CRED) (2003). Disaster Criteria (on-line). http://www.emdat.be/explanatory-notes.

Challenger, R., Clegg, C. W. and Robinson, M. A. (2009a). Understanding Crowd Behaviours: Supporting Documentation. Cabinet Office.

Challenger, R., Clegg, C. W. and Robinson, M. A. (2009b). Understanding Crowd Behaviours: Supporting evidence. Cabinet Office.

Chin, W. W., Marcoling, B. L. and Newsted, P. R. (2003). A partial least squares latent variable modeling approach for Measuring Interaction Effects: Results from a Monte Carlo Simulation Study and an Elctronic-Mail Emotion/Adoption Study. Information System Research, 14: 189-217.

Chukwuma, A. and Kingsley, C. (2014). Disaster Risks in Crowded Situations : Contemporary Manifestations and Implications of Human Stampede in Nigeria. International Journal of Liberal Arts and Social Science, 2: 87-98.

Dear, K. and Wang, Z. (2015). Climate and health: Mortality attributable to heat and cold. The Lancet, 386: 320-322.

Diaz, J., Linares, C. and Tobias, A. (2006). A critical comment on heat wave response plans. European Journal of Public Health, 16: 600.

Dickie, J. F. (1995). Major crowd catastrophes. Safety Science, 18: 309-320.

DiPasquale, D. and Glaeser, E. L. (1996). The L.A. Riot and the Economics of Urban Unrest. NBER Working Paper Series (on-line): 38-. 
http://papers.nber.org/papers/w5456.pdf.

Fruin, J. J. (1993). The causes and prevention of crowd disasters. Engineering for crowd safety: $1-10$.

Gaskin, J. (2016). Confirmatory Factor Analysis. Gaskination's StatWiki (on-line). http://statwiki.kolobkreations.com/index.php?title=Confirmatory_Factor_An alysis.

Hair, J. F., Black, W. C., Babin, J. and Anderson, R. E. (2010). Multivariate data analysis (7th ed). Pearson, 2009.

$\mathrm{Hu}$, L. and Bentler, P. M. (1999). Cutoff criteria for fit indexes in covariance structure analysis: Conventional criteria versus new alternatives. Structural Equation Modeling: A Multidisciplinary Journal, 6: 1-55.

International Labour Office (1988). Major Hazard Control: A Practical Manual : an ILO Contribution to the International Programme on Chemical Safety of UNEP, ILO, WHO (IPCS). Cambridge: International Labour Organization, 1988. https://books.google.co.uk/books?id=694e5QW8WRQC.

Kim, D., Lee, K. and Sirgy, J. (2016). Examining the differential impact of human crowding versus spatial crowding on visitor satisfaction at a festival. Journal of Travel \& Tourism Marketing (on-line), 33: 293-312. http://www.tandfonline.com/doi/full/10.1080/10548408.2015.1024914.

Lloyd, K., Rosin, P. L., Marshall, D. and Moore, S. C. (2017). Detecting violent and abnormal crowd activity using temporal analysis of grey level co-occurrence matrix ( GLCM ) -based texture measures. Machine Vision and Applications.

Lowe, D., Ebi, K. L. and Forsberg, B. (2011). Heatwave early warning systems and adaptation advice to reduce human health consequences of heatwaves. International Journal of Environmental Research and Public Health, 8: 4623-4648.

Mehta, V. (2013). The Street: A Quintessential Social Public Space. Routledge, 2013.

Miller, K. (2015). Behind the Mecca Stampede: When Crowd Mentality Meets Panic. Yahoo, 2015.

Moller, N., Hansson, S. O. V. E. and Peterson, M. (2006). Safety is more than the antonym of risk. Journal of Applied Philosophy, 23: 419-432.

Myers, D. G. (1990). Social Psychology (3rd Edition). McGraw-Hill, 1990.

National Disaster Management Authority of India (2014). Managing Crowds: A Guide for Administrators and Organizers of Events and Venues.

Petroski, H. (1992). To Engineer is Human: The Role of Failure in Successful Design.

Rahmat, N., Jusoff, K., Ngali, N., Ramli, N., Md Zaini, Z. M., Samsudin, A., Abd Ghani, F. and Hamid, M. (2011). Crowd Management Strategies and Safety Performance among Sports Tourism Event Venue Organizers in Kuala Lumpur and Selangor. World Applied Sciences Journal, 12: 47-52.

Robine, J. M., Cheung, S. L. K., Le Roy, S., Van Oyen, H., Griffiths, C., Michel, J. P. and Herrmann, F. R. (2008). Death toll exceeded 70,000 in Europe during the summer of 2003. Comptes Rendus - Biologies, 331: 171-178. 
Shaluf, I. M. (2007). Disaster types. Disaster Prevention and Management: An International, 16: 704-717.

Shaluf, I. M. (2008). Technological disaster stages and management. Disaster Prevention and Management, 17: 114-126.

Shaluf, I. M. and Ahmadun, F.-R. (2006). Disaster types in Malaysia: an overview. Disaster Prevention and Management (on-line), 15: 286-298. http://www.emeraldinsight.com/10.1108/09653560610659838.

Shiwakoti, N. and Sarvi, M. (2013). Understanding pedestrian crowd panic: A review on model organisms approach. Journal of Transport Geography (online), 26: 12-17. http://dx.doi.org/10.1016/j.jtrangeo.2012.08.002.

Silvers, J. R. (2008). Risk Management for Meetings and Events (illustrate). Butterworth-Heinemann, 2008.

Sime, J. D. (1999). Crowd facilities, management and communications in disasters. Facilities, 17: 313-324.

Sime, J. D. (1995). Crowd psychology and engineering. Safety Science, 21: 1-14.

Still, G. K. (2016). Crowd safety and Risk analysis (on-line). http://www.gkstill.com/ExpertWitness/CrowdDisasters.html.

The Regional Office for Europe of the World Health Organization (2011). HeatHealth Action Plan. : 60.

Tilly, C. (2004). Terror, Terrorism, Terrorists. In: Sociological Theory. pp.5-13. http://stx.sagepub.com/lookup/doi/10.1111/j.1467-9558.2004.00200.x.

Tseng, Y. P., Kyle, G. T., Shafer, C. S., Graefe, A. R., Bradle, T. a. and Schuett, M. a. (2009). Exploring the crowding-satisfaction relationship in recreational boating. Environmental Management (on-line), 43: 496-507. file://C:/Users/User/Documents/Mendeley Desktop/2009 - Exploring the crowding-satisfaction relationship in recreational boating.pdf.

US DoD (2015). Department of Defense Dictionary of Military and Associated Terms. US Department of Defense Joint Publication, 2001: 1-513. 